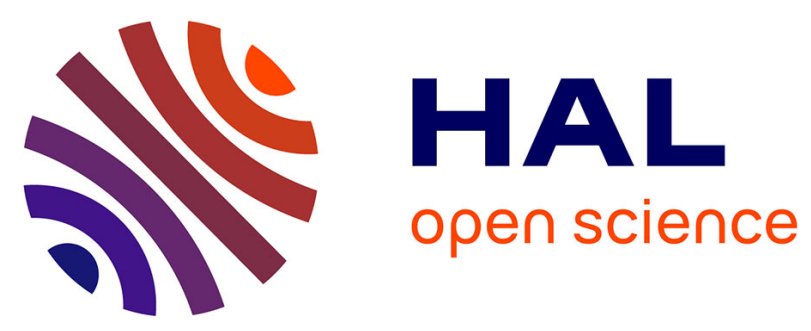

\title{
Advantage of terahertz radiation versus X-ray to detect hidden organic materials in sealed vessels
}

\author{
Maryelle Bessou, Henri Duday, Jean-Pascal Caumes, Simon Salort, Bruno
}

Chassagne, Alain Dautant, Anne Ziéglé, Emmanuel Abraham

\section{To cite this version:}

Maryelle Bessou, Henri Duday, Jean-Pascal Caumes, Simon Salort, Bruno Chassagne, et al.. Advantage of terahertz radiation versus X-ray to detect hidden organic materials in sealed vessels. Optics Communications, 2012, 285 (21-22), pp.4175-4179. 10.1016/j.optcom.2012.07.007 . hal-00731822

\section{HAL Id: hal-00731822 \\ https://hal.science/hal-00731822}

Submitted on 13 Mar 2018

HAL is a multi-disciplinary open access archive for the deposit and dissemination of scientific research documents, whether they are published or not. The documents may come from teaching and research institutions in France or abroad, or from public or private research centers.
L'archive ouverte pluridisciplinaire $\mathbf{H A L}$, est destinée au dépôt et à la diffusion de documents scientifiques de niveau recherche, publiés ou non, émanant des établissements d'enseignement et de recherche français ou étrangers, des laboratoires publics ou privés.

\section{(1)(1) $\$(0)$}

Distributed under a Creative Commons Attribution - NonCommercial - ShareAlikel 4.0 


\title{
Advantage of terahertz radiation versus X-ray to detect hidden organic materials in sealed vessels
}

\author{
Maryelle Bessou ${ }^{a}$, Henri Duday ${ }^{a}$, Jean-Pascal Caumes ${ }^{d}$, Simon Salort ${ }^{b}$, Bruno Chassagne $^{\mathrm{b}}$, \\ Alain Dautant ${ }^{\mathrm{c}}$, Anne Ziéglé ${ }^{\mathrm{d}}$, Emmanuel Abraham ${ }^{\mathrm{e}, *}$ \\ ${ }^{a}$ Univ. Bordeaux, PACEA, UMR 5199, F-33400 Talence, France \\ b ALPhANOV, 351 Cours de la Libération, 33405 Talence, France \\ ' Univ. Bordeaux, IBGC, UMR 5095, F-33077 Bordeaux, France \\ ${ }^{\mathrm{d}}$ Museum of Aquitaine, 20 Cours Pasteur, 33000 Bordeaux, France \\ e Univ. Bordeaux, LOMA,UMR 5798, F-33400 Talence, France
}

\section{A R T I C L E I N F O}

Keywords:

Terahertz imaging

X-ray imaging

Organic materials

Art conservation

Cultural heritage

\section{A B S T R A C T}

Terahertz imaging and conventional X ray have been used to investigate a sealed Ancient Egyptian jar preserved at the Museum of Aquitaine (France). Terahertz radiation revealed an unknown content that could not have been visualized by $\mathrm{X}$ ray. By comparison with a model object, we concluded that this content was composed of organic materials explaining their relative radiolucency.

\section{Introduction}

Art conservation science is a large expertise domain devoting to the preservation and the protection of our cultural heritage. For the restorers, the scientific analysis of art materials provides information about the artist's technique and artefacts history [1,2]. It also allows an accurate material selection for future restoration. For this purpose, various physical methods of diag nosis are available. From UV to infrared, multi spectral imaging methods make it possible the examination of the artwork under different ranges of the electromagnetic spectrum [3 5]. Conven tional $\mathrm{X}$ ray is also considered as an efficient technique with sub millimeter spatial resolution. It provides highly contrasted images depending on the radiodensity of the materials [6,7]. However, the use of $X$ ray is sometimes not recommended regarding to the ionizing power of the radiation and the difficulty of sample radio metric dating after $\mathrm{X}$ ray irradiation [8]. Radiography also requires strict safety rules based on the knowledge of the radiation effects and on the principles of protection. Only licensed users can mani pulate $\mathrm{X}$ ray producing devices and perform radiographic examina tion, respecting safe operating procedures and ensuring the wearing of personal dosimeters. Besides, an under exploited domain of the electromagnetic spectrum, known as the terahertz $(\mathrm{THz})$ spectral

\footnotetext{
* Corresponding author at: Univ. Bordeaux, LOMA, UMR 5798, F-33400 Talence, France. Tel.: + 33 540003122; fax: + 33540006970 .

E-mail address: em.abraham@loma.u-bordeaux1.fr (E. Abraham).
}

region, has recently emerged as a possible powerful candidate in the field of art conservation for the investigation of various art related materials [9]. Being non destructive and contact less in nature, this wave can penetrate into non conductive and non polar materials and offer complementary spectroscopic data for a better diagnosis and understanding of artworks.

In the field of art painting, $\mathrm{THz}$ imaging has already shown a great ability for the analysis of pigments [ $\left.\begin{array}{ll}10 & 12\end{array}\right]$ and preparation layers [13 16], the evaluation of mural paintings [17] or for the character recognition in medieval manuscripts [18]. THz imaging has been used for the analysis of Ancient Egyptian mummy [19], written papyrus [20] and clay artefacts [21]. For dendrochronol ogy applications, $\mathrm{THz}$ imaging was applied for tree ring analysis $[22,23]$. In 2009, Adam et al. have compared $\mathrm{THz}$ imaging of painting with $X$ ray and infrared reflectography [24]. They con firmed that $\mathrm{THz}$ radiation can give information on the thickness of hidden paint layers. They also observed that $\mathrm{X}$ rays do not easily penetrate layers of high density pigments, such as lead paint, which is ubiquitous in historical painting. More recently, Fuku naga et al. reported the first use of $\mathrm{THz}$ time domain reflection imaging for the analysis of textiles of an Egyptian human mummy preserved at the Metropolitan Museum of Art (New York) [25]. They pointed out the difficulty of conventional $X$ ray to visualize the bandages due to the low radiological contrast of the fabric layers. Except these two studies, to our knowledge, no other results have been published concerning the direct comparison between $\mathrm{THz}$ and $\mathrm{X}$ ray imaging applied to art related materials. 
In this paper, we propose to demonstrate the high potential of $\mathrm{THz}$ imaging for the analysis of ancient clay artefacts. Especially, we analyze a 3500 years old sealed clay jar from Ancient Egypt preserved at the Museum of Aquitaine (Bordeaux, France). In a previous work, 3D tomographic imaging of the jar had been successfully performed using a specific reconstruction algorithm $[26,27]$. In the present study, we provide an experimental evi dence of the specificity of $\mathrm{THz}$ imaging compared to conventional $X$ ray in order to analyze the inner volume of the sealed artifact. More generally, we establish that $\mathrm{THz}$ imaging is a well suited and sustainable method for the detection of hidden materials contained in sealed vessels.

\section{Experimental methods and investigated material}

The experimental setup of the continuous wave $\mathrm{THz}$ imaging system shortly called the "THz scanner" has already been described [28]. Briefly, it consists of a compact millimeter wave Gunn diode $(110 \mathrm{GHz}, 20 \mathrm{~mW})$ coupled with a horn antenna (Fig. 1(a)). The output beam is focused on the sample which is positioned on two axes $X Y$ motorized stages. At the sample position, the beam diameter is diffraction limited and the final image is obtained point by point by raster scanning the sample in both horizontal and vertical directions. For the detection, we used a commercial low cost pyroelectric sensor (Spectrum Detector Inc.) and an optical chopper connected to a lock in amplifier. A 2D transmission image of the sample is obtained by moving the object in the $X$ and $Y$ directions with a scan step of $2 \mathrm{~mm}$ in both directions. With a scan speed of 5 pixels/s, the acquisition time for a $(100 \times 100)$ pixels image size is about $30 \mathrm{~min}$. This portable $\mathrm{THz}$ scanner is well adapted for on site imaging since its volume is about $(500 \times 500 \times 500) \mathrm{mm}^{3}$ with a total weight less than $20 \mathrm{~kg}$. Moreover, as pointed out in the Introduction, the imaging system is easy to install and completely safe for the sample and the operator, unlike radiography.

For standard radiography, we used a medical $\mathrm{X}$ ray tube including a rotating anode with a tungsten rhenium target on a molybdenum core. In order to properly visualize the structural characteristics of the object and its eventual content, three experi mental parameters were selected: $50 \mathrm{kV}$ (accelerating voltage or potential difference between the anode and the cathode of the $\mathrm{X}$ ray tube, i.e. the penetrating power), $50 \mathrm{~mA}$ (tube current) and $25 \mathrm{mAs}$ (beam intensity related to the exposure time).

The portable THz scanner has been installed in the Museum of Aquitaine (Bordeaux, France) in order to performed on site $\mathrm{THz}$ imaging in collaboration with curators. There, many historic art samples have been scanned from Ancient Egyptian and Roman objects to more contemporary ones such as African fetishes [29]. In this study, we focus on a small Egyptian terracotta jar from the
XVIIIth Dynasty (inventory number 8608). Its size is $97 \mathrm{~mm}$ in height with a maximum diameter of $64 \mathrm{~mm}$ (Fig. 1(b)). Without any specific decoration, it looks like a simple red clay vessel hermetically sealed with a clay cork. A sticker under the object indicates that it was purchased in 1861 in Gournah, on the famous necropolis of Thebes (on the west bank of Luxor) [30]. The existence of the Menkheperre Tuthmosis III's cartouche (1479 1425 B.C.) on the jar clay cork allows to infer that this important object was probably used during the pharaoh's funer ary rituals. However, its real purpose still remains an opened question for the curators.

\section{Results and discussion}

First, we investigated the transmission properties of earthen material at $110 \mathrm{GHz}$ in order to quantify the amplitude of the transmitted signal as a function of the sample thickness. For this purpose, we used terracotta from Salernes (Provence, France), a red ferruginous clay purchased in a pottery shop. The greenware was shaped into parallelepiped slices of different thicknesses from 4 to $33 \mathrm{~mm}$, which were then fired in a kiln at $900{ }^{\circ} \mathrm{C}$ during $5 \mathrm{~h}$. The inserted photograph in Fig. 2 presents the unglazed final bisques. For the measurements, the slices were simply positioned into the $\mathrm{THz}$ scanner and illuminated by the $110 \mathrm{GHz}$ radiation at normal incidence.

The absorbance at $110 \mathrm{GHz}$ as a function of the sample thickness is shown in Fig. 2. The classical calculation Absorbance $=\log \left(I_{0} / I\right)$ has been used, where $I_{0}$ is the transmitted signal measured without any sample and $I$ is the transmitted signal measured in the presence of the sample. We can observe a linear increase of the absorbance as a function of the sample thickness, which indicates that the attenuation of the transmitted signal follows the Beer Lambert's law. Assuming that the samples are made of homogeneous terra cotta, we can estimate the $110 \mathrm{GHz}$ absorption coefficient $\alpha$ of the clay according to the expression Absorbance $=\alpha d$ where $d$ is the sample thickness. The linear fit of the experimental data, including experimental error bars, gives $\alpha=0.9 \pm 0.1 \mathrm{~cm}^{-1}$ (red line in Fig. 2). Also, considering that the noise level of the detection system corresponds to an absorbance of 4.2 , as indicated by the horizontal green line in Fig. 2, we can estimate that, for this material, the maximum sample thickness that can be studied in transmission mode is about $36 \mathrm{~mm}$ (vertical green line in Fig. 2). Even if this result is specific to the Provence terracotta purchased in this study, we can assert that it could be roughly generalized to most clay materials and conclude that the THz scanner described in this paper could be used to analyze most standard terracotta pottery whose global wall thickness is in the order of few centimeters.

Fig. 3(a) presents the $\mathrm{THz}$ transmission image of the jar in a horizontal position (the gray scale level corresponds to the
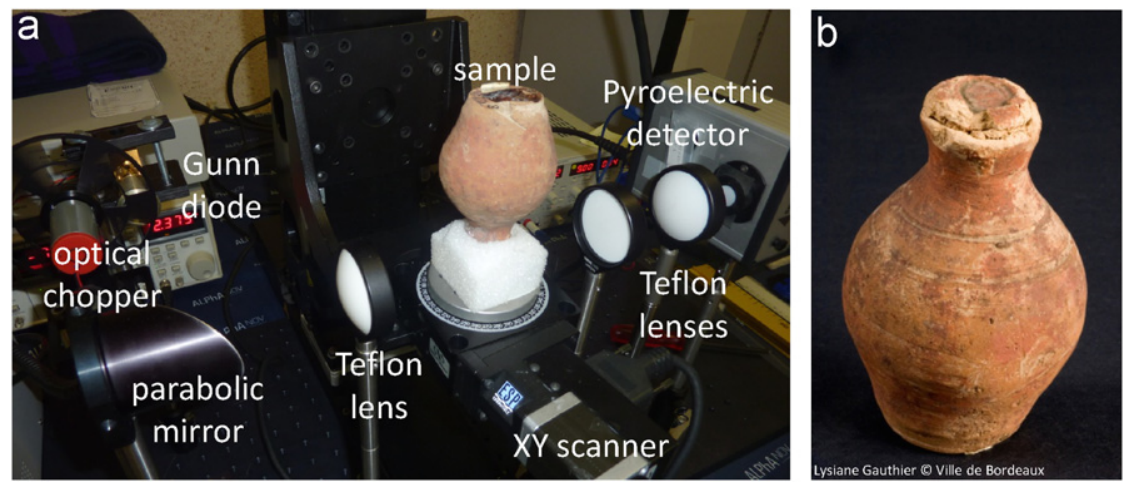

Fig. 1. (a) Experimental setup. Teflon lens $\left(f^{\prime} \quad 60 \mathrm{~mm}\right)$, off-axis parabolic mirror $\left(f^{\prime}\right.$ $150 \mathrm{~mm}$ ). (b) Photograph of the Egyptian jar (inventory number 8608). 
absorbance at $110 \mathrm{GHz}$, calculated as explained previously, with the white color indicating a high absorbance or low transmission). This configuration has been selected in order to determine the presence of eventual contents. Due to gravitation effects, a mobile content should move depending on the orientation of the object. The $\mathrm{THz}$ image clearly reveals that the sealed vessel contains two independent masses, one attached to the bottom and another one free to move inside the inner volume. From Fig. 3(a), we can also surely affirm that the mobile content is deformable since its shape can fit the inner contour of the pottery bottle. According to Egyptologists, the contents cannot be attributed to viscera

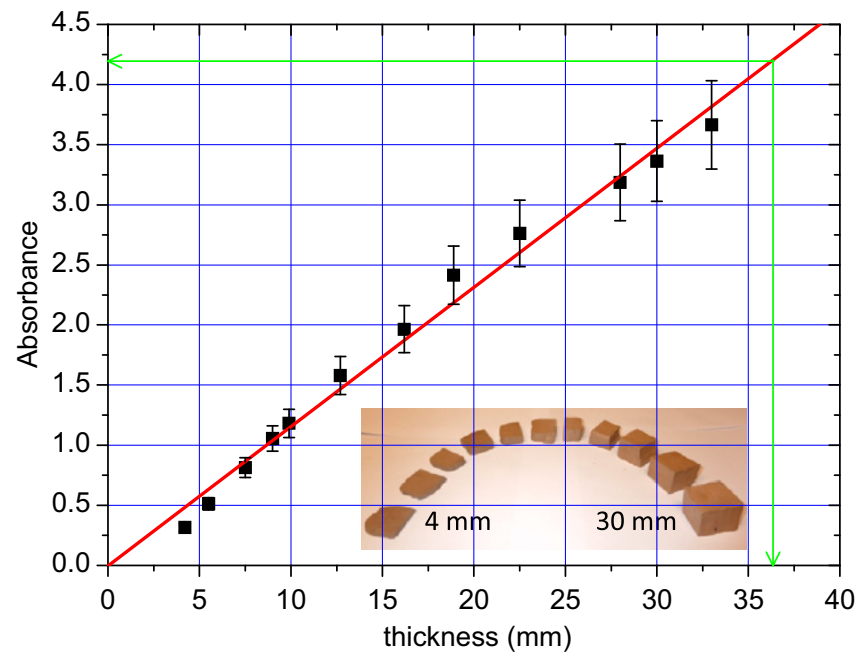

Fig. 2. Absorbance at $110 \mathrm{GHz}$ of terracotta, as a function of sample thickness Insert: photograph of the 11 terracotta slices from 4 to $30 \mathrm{~mm}$. The additional $33 \mathrm{~mm}$ thickness was obtained by turning the $30 \mathrm{~mm}$ slice. Red line: linear fit of the experimental data points, horizontal green line: noise level, and vertical green line: maximum sample thickness being detected by the system. usually preserved in canopic jars but most likely to dried organic materials, as food offerings from funerary rituals. A more precise analysis of the $\mathrm{THz}$ transmitted signal can be obtained from the vertical intensity profile measured along the red line drawn in Fig. 3(a). The corresponding absorbance plot (measured at $110 \mathrm{GHz}$ ) is shown in Fig. 3(b). Inside the jar, in the region corresponding to the empty part (region A in Fig. 3, $x=55$ $65 \mathrm{~mm}$ ), the absorbance is around 0.9. If we consider that the total thickness of the jar walls is around $10 \mathrm{~mm}(5 \mathrm{~mm}$ on each side of the vessel), this absorbance is in good agreement with the previous measurement presented in Fig. 2. Inside the jar, in the region corresponding to the mobile content (region B in Fig. 3, $x=2040 \mathrm{~mm}$ ), the absorbance increases up to 1.92 .8 , indicating that the intrinsic absorbance at $110 \mathrm{GHz}$ of the content can be estimated to 1 1.9. If we suppose that the $\mathrm{THz}$ propagation length into this content is around $20 \mathrm{~mm}$, confirmed by the previous 3D tomographic imaging of the vessel [27], we can roughly estimate that the $110 \mathrm{GHz}$ absorption coefficient of the material constitut ing the mobile content is $\alpha=0.5-0.95 \mathrm{~cm}^{-1}$.

The radiograph of the object is presented in Fig. 3(c), with a similar logarithmic scale representation and a white color for a high absorbance. The observation of the radiological image reveals the outer shape of the vessel, with a compact and dense clay cork and a low transmission in the bottom part of the jar, due to the increase of the pottery's thickness in this region. However, the jar content cannot be revealed by $\mathrm{X}$ ray owing to the higher radiodensity of the clay walls. This reinforces the assumption that this content, clearly revealed by $\mathrm{THz}$ imaging, could consist of dried organic materials (i.e. containing mainly light atoms like $\mathrm{C}, \mathrm{H}, \mathrm{O}, \mathrm{N}$ ) presenting low radiological contrasts correlated to their low atomic numbers. The absorbance plot, obtained from the vertical intensity profile measured along the red line drawn in Fig. 3(c), is shown in Fig. 3(d). From this curve, we can observe that the absorbance is very low inside the jar (about 0.03 from $x=20 \mathrm{~mm}$ to $x=60 \mathrm{~mm}$ ). This indicates that the high radiopacity of the pottery walls completely masks the organic content of the jar.
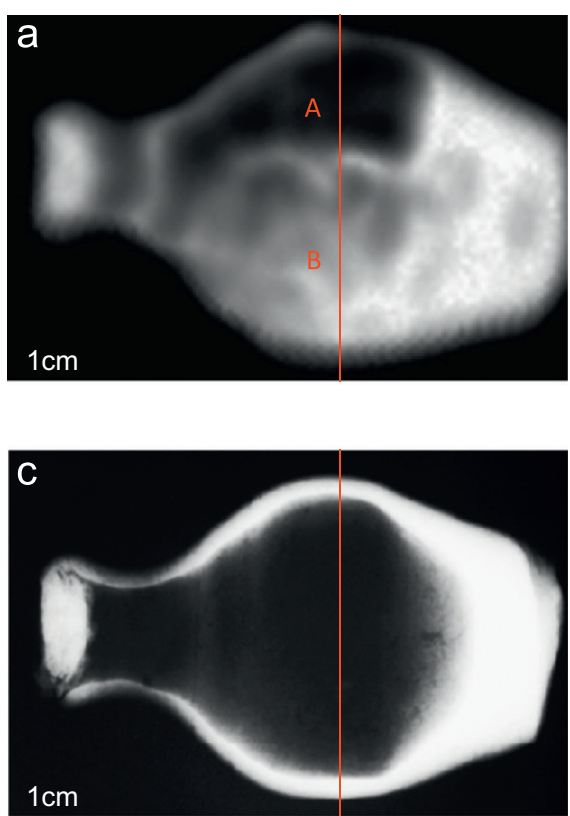
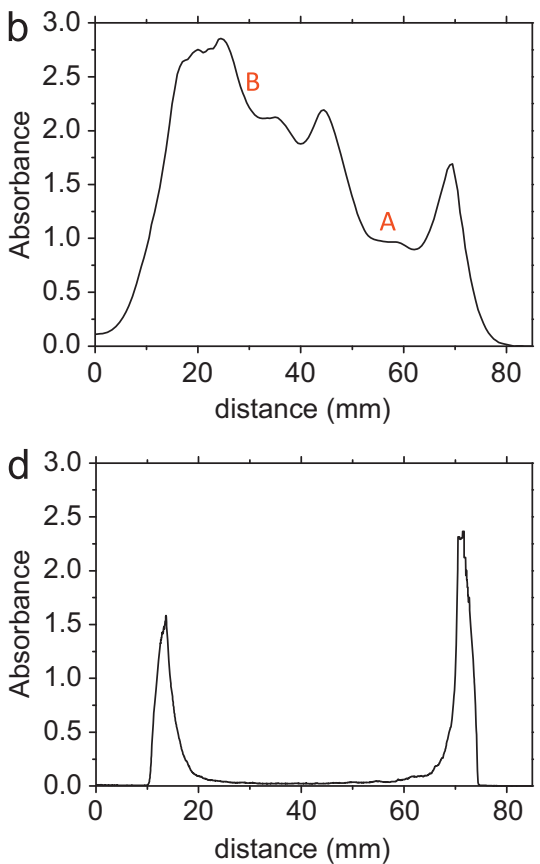

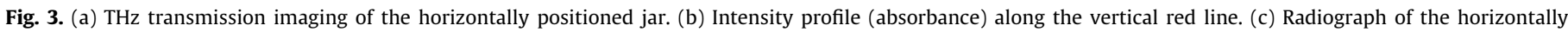
positioned jar. (d) Intensity profile (absorbance) along the vertical red line. 
In order to confirm the ability of $\mathrm{THz}$ radiation to reveal the presence of organic materials embedded into a piece of pottery, by mutual agreement with the museum, we selected another pot used as a model object. The vessel is a red clay pottery coming from Mali (Fig. 4). Its size is $104 \mathrm{~mm}$ in height with a maximum diameter of $118 \mathrm{~mm}$. Various materials have been inserted into the pot and subsequently imaged with the $\mathrm{THz}$ scanner and conventional $\mathrm{X}$ ray. The presentation of the experimental results is organized as follows (Fig. 4). Horizontally, we presented the different experimental vision methods: (a) the photographs of the samples with different added contents, (b) the radiographs, (c) the $\mathrm{THz}$ images, and (d) the differential $\mathrm{THz}$ images corre sponding to the subtraction between the filled pot and the empty one, in order to exhibit the specific contribution of the internal content. Vertically, we presented the different materials inserted into the object and their related images: (1) empty pot, (2) pot with dried flowers, (3) pot with pine bark, (4) pot with hazel wood slice (11 mm thick), and (5) pot with white sand.

First, for the empty pot, both $\mathrm{THz}$ and $\mathrm{X}$ ray images are similar, except the expected higher spatial resolution for the radiography. The images reveal the higher transmission of the radiations in the lower part of the object with respect to the upper part. This is explained by the thickness variations of the pottery wall. Then, the presence of dried flowers or pine bark into the vessel can be only visualized by $\mathrm{THz}$ imaging. Particularly, the differential $\mathrm{THz}$ images clearly reveal the position of the content after the subtraction of the pottery container. With $\mathrm{X}$ ray, as already indicated in the previous section, a relatively high accelerating voltage was selected $(50 \mathrm{kV})$ in order to properly visualize the morphological characteristics of the object. We also tested other physical parameters but finally, whatever the choice, the organic materials inserted into the pottery still remain completely radi olucent. This important result, previously noticed in the case of the Egyptian jar, demonstrates the ability of $\mathrm{THz}$ imaging to identify soft materials embedded into ceramic objects. Next, the wood slice is again clearly visible with $\mathrm{THz}$ radiation and slightly distinguished by $\mathrm{X}$ ray owing to the relatively large thickness and higher density of the added sample. Finally, in order to compare the ability of both methods to image an inorganic inserted material into the pot, we used some white sand, which presents a much higher absorption to $\mathrm{X}$ ray. In this case, as expected, both $\mathrm{THz}$ and $\mathrm{X}$ ray imaging can reveal the presence of this inorganic compound into the pot. According to these additional tests, we can conclude that, in contrast to $\mathrm{THz}$ radiation, the assessment of the content is not possible with $\mathrm{X}$ ray if it is composed of organic materials, since the high radiopacity of the pottery walls strongly affects the visualization of the content until to completely mask it. Moreover, the important conclusion of these experimental results concerns the confirmation of the organic nature of the Egyptian jar content. With this study, we confirmed that $\mathrm{THz}$ imaging is more adapted than $\mathrm{X}$ ray to reveal different classes of organic materials into a piece of pottery, since, at least at $110 \mathrm{GHz}$, the absorption coefficients of both terracotta and organic compounds are in the same order of magnitude, as experimentally measured with the Egyptian jar.

\section{Conclusion}

In this current comparative and experimental study, we demon strated the capability of $\mathrm{THz}$ imaging for analyzing a XVIIIth Dynasty Egyptian sealed vessel, preserved at the Museum of Aquitaine. We pointed out that $\mathrm{THz}$ radiation can reveal contents that could not have been imaged by conventional $X$ ray, since this method cannot detect radiolucent materials inserted into high radiodense ones. By comparison with a model object, we concluded that the content of the Egyptian jar was composed by dried organic materials. More generally, these results expand the high potential of $\mathrm{THz}$ imaging for the detection of hidden organic materials into ceramic objects. Especially, for the investigation of Egyptian antiquities, $\mathrm{THz}$ imaging would be more efficient than radio graphy for the completely non invasive analysis of canopic jars used as specific containers by the Egyptians to store and preserve the viscera during the rituals of mummification. a

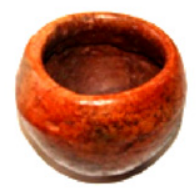

(2)

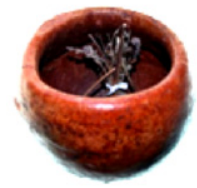

(3)

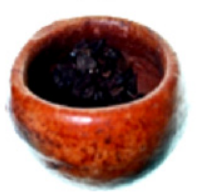

(4)

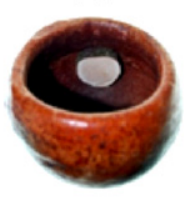

(5)

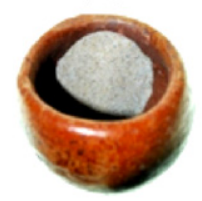

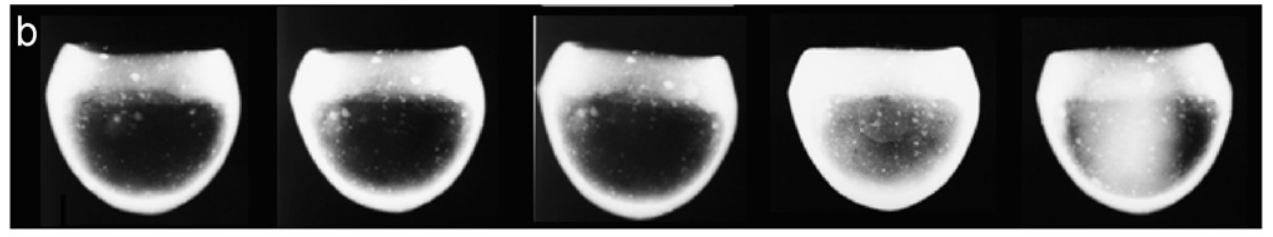

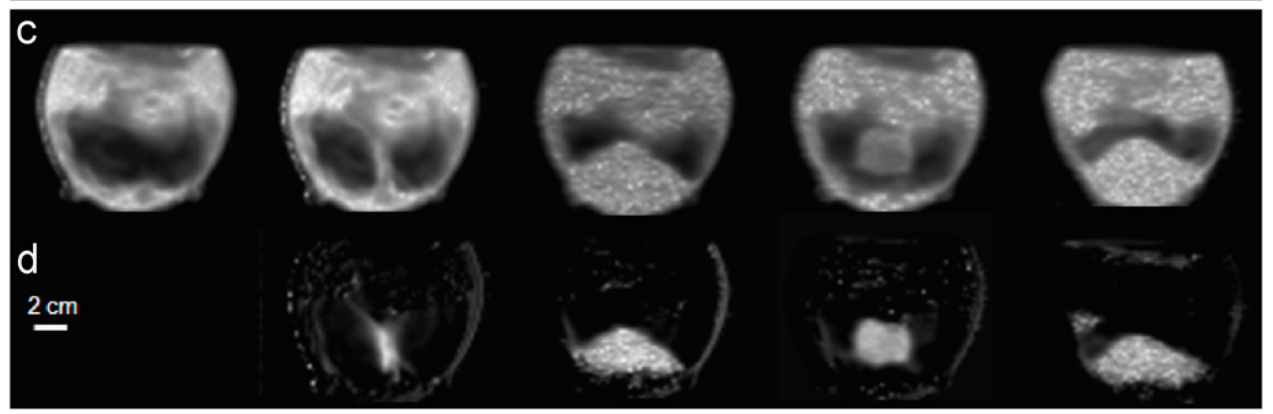

Fig. 4. (a) Photographs of model objects. (b) Radiographs. (c) THz imaging. (d) Differential THz imaging (subtraction image between filled jar and empty one). (1) Empty pot, (2) pot with dried flowers, (3) pot with pine bark, (4) pot with hazel wood slice (11 mm thick), and (5) pot with white sand. 


\section{Acknowledgments}

The authors gratefully acknowledge François Hubert Director of the Museum of Aquitaine and the city of Bordeaux for the authorization to perform the measurements at the museum. They also acknowledge Masahiko Tsukada (Metropolitan Museum of Art, New York) for fruitful discussions. This work was supported by the Action Interdisciplinaire de Recherche "Archéométrie" (TeraScan project, CNRS, France).

\section{References}

[1] E. Pye, Caring for the Past: Issues in Conservation for Archaeology and Museums, James \& James, London, 2001.

[2] A. Adriaens, Spectrochimica Acta Part B 60 (2005) 1503.

[3] R.J.H. Clark, Applied Physics A 89 (4) (2007) 833.

[4] J.K. Delaney, J.G. Zeibel, M. Thoury, R. Littleton, M. Palmer, K.M. Morales, E.R. de la Rie, A. Hoenigswald, Applied Spectroscopy 64 (6) (2010) 584.

[5] C. Fischer, I. Kakoulli, Reviews in Conservation 7 (2006) 3.

[6] O. Hahn, Studies in Conservation 50 (2005) 23.

[7] M.P. Morigi, F. Casali, M. Bettuzzi, R. Brancaccio, V. d'Errico, Applied Physics A 100 (3) (2010) 653.

[8] M.J. Aitken, Thermoluminescence Dating, Academic Press, London, 1985.

[9] J.B. Jackson, J. Bowen, G. Walker, J. Labaune, G. Mourou, M. Menu, K. Fukunaga, IEEE Transactions on Terahertz Science and Technology 1 (1) (2011) 220.

[10] K. Fukunaga, Y. Ogawa, S. Ayashi, I. Osako, IECE Electronics Express 4 (8) (2007) 258.

[11] K. Fukunaga, N. Sekine, I. Osako, N. Oda, H. Yoneyama, T. Sudoh, Journal of the European Optical Society: Rapid Communications 3 (2008) 08027.

[12] E. Abraham, A. Younus, J.-C. Delagnes, P. Mounaix, Applied Physics A 100 (3) (2010) 585.

[13] M. Mizuno, K. Fukunaga, S. Saito, I. Osako, Journal of the European Optical Society: Rapid Communications 4 (2009) 09044.
[14] E. Abraham, A. Younus, A. El Fatimy, J-C. Delagnes, E. Nguéma, P. Mounaix, Optics Communication 282 (2009) 3104

[15] K. Fukunaga, K. Osako, Y. Kohdzuma, T. Koezuka, M.-J. Kim, T. Ikari, X. Du, Journal of the European Optical Society: Rapid Communications 5 (2010) 10024.

[16] K. Fukunaga, M. Picollo, Applied Physics A 100 (2010) 591.

[17] J.B. Jackson, M. Mourou, J.F. Whitaker, I.N. Duling III, S.L. Williamson, M. Menu, G.A. Mourou, Optics Communication 281 (2008) 527.

[18] K. Fukunaga, Y. Ogawa, S. Hayashi, I. Hosako, IEICE Electronics Express 5 (2008) 223.

[19] L. Öhrström, A. Bitzer, M. Walther, F.J. Rühli, American Journal of Physical Anthropology 142 (3) (2010) 497.

[20] J. Labaune, J.B. Jackson, S. Pagès-Camagna, I.N. Duling, M. Menu, G.A. Mourou, Applied Physics A 100 (3) (2010) 607.

[21] J. Labaune, J.B. Jackson, K. Fukunaga, J. White, L. d'Alessandro, A. Whyte, M. Menu, G.A. Mourou, Applied Physics A 105 (1) (2011) 5.

[22] M. Koch, S. Hunsche, P. Schumacher, M.C. Nuss, J. Feldmann, J. Fromm, Wood Science and Technology 32 (1998) 421.

[23] J.B. Jackson, M. Mourou, J. Labaune, J.F. Whitaker, I.N. Duling III, S.L. Williamson, C. Clavier, M. Menu, G.A. Mourou, Measurement Science and Technology 20 (2009) 075502.

[24] A.J.L. Adam, P.C.M. Planken, S. Meloni, J. Dik, Optics Express 17 (2009) 3407.

[25] K. Fukunaga, E. Cortes, A. Cosentino, I. Stünkel, M. Leona, I.N. Duling III, D.T. Mininberg, Journal of the European Optical Society: Rapid Communications 6 (2011) 11040.

[26] B. Recur, A. Younus, S. Salort, P. Mounaix, B. Chassagne, P. Desbarats J.-P. Caumes, E. Abraham, Optics Express 19 (6) (2011) 5105.

[27] J.-P. Caumes, A. Younus, S. Salort, B. Chassagne, B. Recur, Anne Ziéglé, A. Dautant, E. Abraham, Applied Optics 50 (20) (2011) 3604.

[28] A. Younus, S. Salort, B. Recur, P. Desbarats, P. Mounaix, J.-P. Caumes, E. Abraham, in: K.A. Krapels, N.A. Salmon (Eds.), Millimetre Wave and Terahertz Sensors and Technology III, Proc. SPIE, vol. 7837, 2010, p. 783709.

[29] A. Younus, J.-P. Caumes, S. Salort, B. Chassagne, A. Dautant, A. Ziéglé, E. Abraham, Advances in Optical Technologies 50 (2011) 9.

[30] F. Saragoza, Revue archéologique de Bordeaux, tome IC, 2008, p. 131 (French) 